\title{
DESCONTINUIDADE FLUVIAL: ESTUDO DE CASO NO RIO PIRAPOZINHO (SP)
}

Bruno Frias Faga, Renata Ribeiro de Araujo.

Engenharia Ambiental. Departamento de Planejamento, Urbanismo e Ambiente da UNESP - Presidente Prudente. Email: bfagant@globo.com . Fundação de Amparo à Pesquisa do Estado de São Paulo (FAPESP).

\section{RESUMO}

A presente pesquisa teve como principal objetivo testar a Teoria Ecológica da Imparidade com o Descontínuo Fluvial no Rio Pirapozinho após o lançamento de efluente tratado pela estação de tratamento de esgotos. Para tanto foi utilizada a modelagem matemática de Streeter-Phelps (1925) para verificação do comportamento do processo de autodepuração. Foi realizado estudo de campo, em que se analisaram variáveis limnologicas em 5 seções do Rio Pirapozinho (4 no rio principal e 1 no tributário), além de monitorar as características do efluente que estava sendo lançado na região. Foram amostradas as seguintes variáveis limnologicas: demanda bioquímica de oxigênio (DBO), oxigênio dissolvido (OD), vazão e temperatura das aguas. Percebeu-se uma forte correlação da teoria da imparidade com o descontinuo fluvial com os efeitos gerados pela entrada do efluente e tributários no Rio Pirapozinho.

Palavras-chave: Autodepuração. Teoria da imparidade com o descontinuo fluvial. Modelagem Streeter-Phelps.

\section{INTRODUÇÃO}

$\mathrm{Na}$ atualidade, onde crescimento industrial e populacional tem que estar aliado à preservação do meio ambiente, é importante analisar muito bem o despejo de efluentes em um determinado corpo d'água, considerando sua capacidade de autodepuração. Isso deve ocorrer, já que após a entrada da fonte poluidora, o equilíbrio entre as comunidades é afetado, resultando em uma desorganização inicial, seguida por uma tendência posterior à organização. "Essa capacidade de recuperar naturalmente o equilíbrio aquático é denominada autodepuração (VON SPERLING, 2007)". No entanto, na atualidade, grande parte dos corpos hídricos recebem quantidades de efluentes muito acima da sua real capacidade de depuração, gerando assim, cenários de degradação intensa.

De maneira mais especifica, o processo autodepurativo ocorre de maneira e intensidades distintas, de acordo com as características do corpo hídrico em questão. Dessa forma, Mota (2003) enumera alguns parâmetros que afetam a eficácia da autodepuração, tais como: turbulência da água, temperatura e vazão.

Ademais, Braga et al. (2005) ressaltam a existência de uma área relativamente sadia do corpo hídrico, se não houver poluição anterior, localizada em região a montante do lançamento de carga poluidora. No entanto, após o acondicionamento do efluente com elevada carga orgânica 
biodegradável no curso hídrico, Von Sperling (2007) destaca ao menos quatro zonas de depuração distintas, que são: zona de degradação, zona de decomposição ativa, zona de recuperação e zona de águas limpas.

Este cenário de criação de zonas distintas no ambiente lótico pode ser explicado pela teoria ecológica da Imparidade com o Descontínuo Fluvial, apresentada por Poole (2002). Relacionado a essa teoria, Silva (2010), a resume de maneira bastante objetiva, afirmando que os sistemas aquáticos lóticos são únicos tanto em estrutura quanto em função, quando observada a escala de uma bacia hidrográfica.

“Assim, a bacia é formada por manchas que são características de cada segmento (vegetação, sedimentos, fluxo, solo, etc.), e a dinâmica dessas manchas ao longo do sistema é que caracteriza o rio (Siqueira \& Henry-Silva, 2011)". Poole (2002) destaca que um contínuo, desde a nascente até a foz, é uma representação razoável para um rio, principalmente quando analisadas as considerações feitas por Vannote et al. (1980), no entanto, nenhum rio, quando analisado detalhadamente pode ser apresentado como um contínuo.

“Os tributários, além das barragens e outros empreendimentos, são um fator de interferência no gradiente longitudinal do rio, dessa forma, cada bacia possui seu próprio mosaico de manchas denominados de meta-estrutura, e um rio nunca seria um contínuo, pois as manchas se comportam de modo bastante desigual no contexto geral (BARBOSA \& SPÍNOLA, 2003)”. Poole (2002) destaca que junções com tributários criam "buracos" na sucessão esperada de habitats a jusante, exemplificando as manchas que acima são destacadas como base da teoria da imparidade com descontínuo fluvial.

Diante do exposto, a presente pesquisa apresenta o estudo da capacidade de autodepuração do Rio Pirapozinho (SP) após despejo de efluente tratado pela Estação de Tratamento de Esgotos do município de Pirapozinho/SP, com o objetivo de verificar se ocorre descontinuidade fluvial de acordo com a Teoria Ecológica da Imparidade com o Descontínuo Fluvial, proposta por Poole (2002).

\section{METODOLOGIA}

Para o desenvolvimento da presente pesquisa foi necessário realizar trabalho de campo. Em primeiro lugar, para as análises relacionadas à autodepuração do rio Pirapozinho, no município de Pirapozinho/SP, de acordo com a modelagem matemática de Streeter-Phelps (1925), foram monitoradas seções a $100 \mathrm{~m}$ a montante do lançamento da ETE local (seção 1) e do efluente que 
estava sendo lançado pela ETE. As variáveis limnológicas amostradas foram vazão (Q), oxigênio dissolvido $(O D)$, demanda bioquímica de oxigênio (DBO).

Também foram feitas amostragens das mesmas variáveis na seção 2 , a $20 \mathrm{~m}$ a jusante do lançamento da ETE, bem como na seção 3, que estava localizada em um tributário do Rio Pirapozinho.

As seções 4 e 5 foram utilizadas somente como controle da modelagem matemática, sendo que as variáveis mensuradas foram somente OD e DBO. A temperatura foi importante para 0 ajuste das constantes $k_{1}, k_{2}$ e $k_{d}$, que são essenciais no desenvolvimento da modelagem matemática proposta.

Quadro 1. Variáveis amostradas e respectivos metodologias.

\begin{tabular}{|l|l|l|}
\hline Variável & Unidade & Metodologia \\
\hline Temperatura & $\left({ }^{\circ} \mathrm{C}\right)$ & Termômetro \\
\hline DBO & $\left(\mathrm{mg} . \mathrm{L}^{-1}\right)$ & Stardard of Methods (1998) \\
\hline Profundidade & $(\mathrm{m})$ & Régua Métrica \\
\hline OD & $\left(\mathrm{mg} . \mathrm{L}^{-1}\right)$ & Oximetro Digital Portatil \\
\hline
\end{tabular}

Além das variáveis indicadas no Quadro 1, a vazão $\left(\mathrm{m}^{3}\right)$ das seções também foram mensuradas. Para mensuração da vazão foi necessário realização de duas etapas sequenciais: primeiramente fez-se uma batimetria da seção do rio, o que viabilizou o cálculo da área transversal da seção (A). Em seguida, marcou-se 1 metro com uma trena, posicionando um objeto flutuante na origem e medindo, com o auxílio de um cronômetro, o tempo que este levava para percorrer o metro medido, possibilitando a determinação da velocidade (Vm). Em seguida, recorreu-se a equação 1 para o cálculo da vazão média $(Q)$ do trecho do curso d'água em questão.

$$
Q=A \cdot V m \quad \text { (equação } 1)
$$

Para a aplicação da modelagem matemática de Streeter \& Phelps (1925), foi confeccionada uma planilha eletrônica utilizando o Microsoft Excel 2010, conforme metodologia proposta por Von Sperling (2007). A plotagem dos gráficos, proposta por Von Sperling (2007) foi feita com o programa Origin Pro 8. Como foram obtidos dados de campo e através da modelagem matemática de Streeter-Phelps (1925), a teoria da imparidade com o descontínuo fluvial foi associada ao curso d'água em questão. 


\section{RESULTADOS}

Os resultados de oxigênio dissolvido, demanda bioquímica de oxigênio e vazão das seções amostradas estão apresentados na Tabela 1.

Tabela 1. Dados coletados em campo

\begin{tabular}{|l|l|l|l|}
\hline Localidade & OD $(\mathrm{mg} / \mathrm{L})$ & DBO $(\mathrm{mg} / \mathrm{L})$ & Vazão $\left(\mathrm{m}^{3} / \mathrm{s}\right)$ \\
\hline Seção 1 & 6,16 & 8 & 0,0064 \\
\hline Seção 2 & 4,02 & 103 & 0,060 \\
\hline Seção 3 & 3,39 & 18 & 0,073 \\
\hline Seção 4 & 2,90 & 85 & 0,15 \\
\hline Seção 5 & 2,05 & 80 & 0,16 \\
\hline Efluente da ETE & 0,32 & 210 & 0,050 \\
\hline
\end{tabular}

Quando se faz qualquer estudo relacionado a autodepuração de corpos d'agua, é necessário evidenciar os dados de entrada que foram utilizados no decorrer do processamento. Primeiramente, destaca-se que as constantes $k_{1}, k_{2}$ e $k_{d}$, adotadas segundo Von Sperling (2007), tiveram os valores de $0,22 \mathrm{~d}^{-1} ; 0,20 \mathrm{~d}^{-1}$ e $1,55 \mathrm{~d}^{-1}$, respectivamente. Os outros valores utilizados estão resumidos na Tabela 1 , sendo importante destacar que estes foram obtidos diretamente através de coletas de campo, não obtidos portanto, com os dados gerados pela modelagem matemática de Streeter-Phelps (1925).

As figuras 1 e 2, obtidas através da modelagem matemática, apresentam os perfis de depuração do Rio Pirapozinho antes do encontro com seu tributário, já tendo recebido efluente tratado pela estação de tratamento de esgotos.

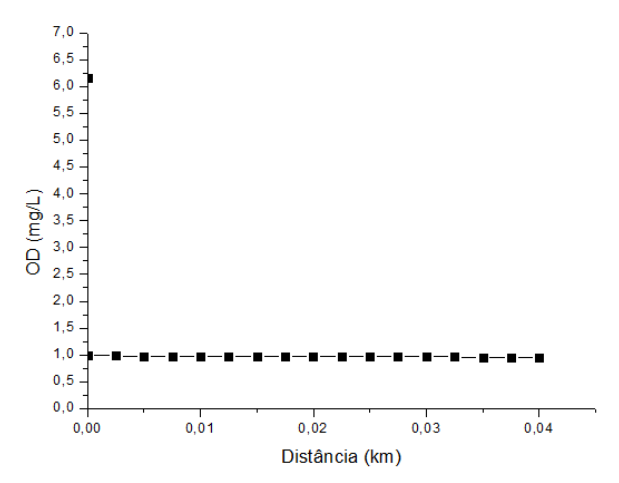

Figura 1. OD antes da entrada do tributário.

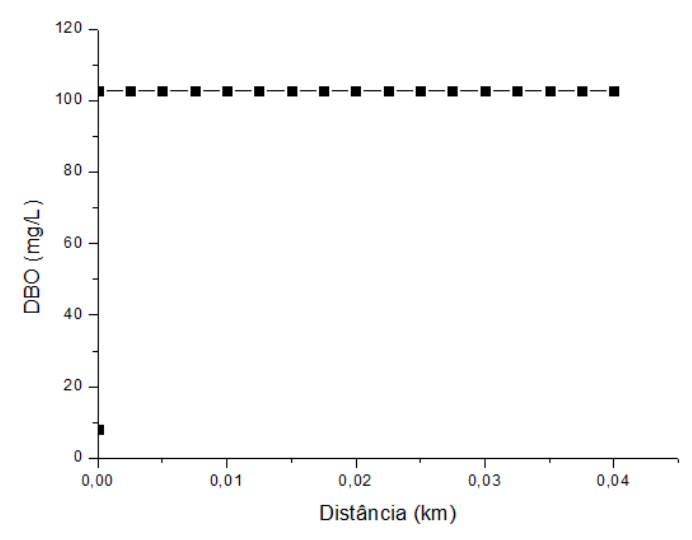

Figura 2. DBO antes da entrada do tributário. 
Os resultados de oxigênio dissolvido e de demanda bioquímica de oxigênio após confluência do Rio Pirapozinho com seu tributário preditos na modelagem matemática estão apresentados nas Figuras 3 e 4.

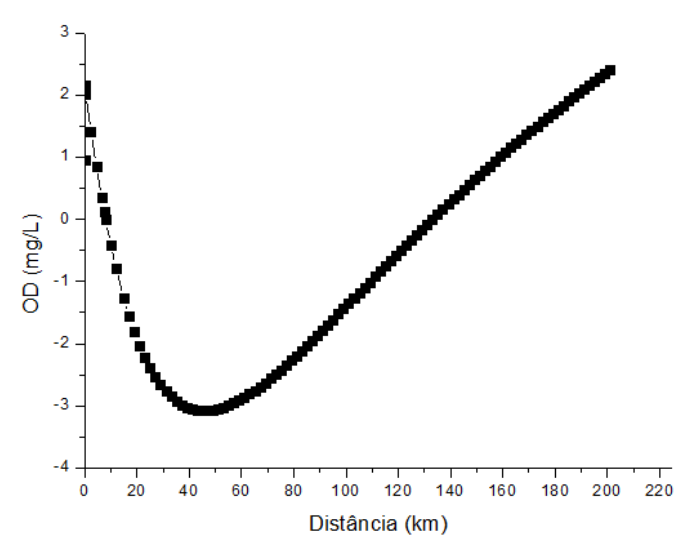

Figura 3. OD após entrada do tributário

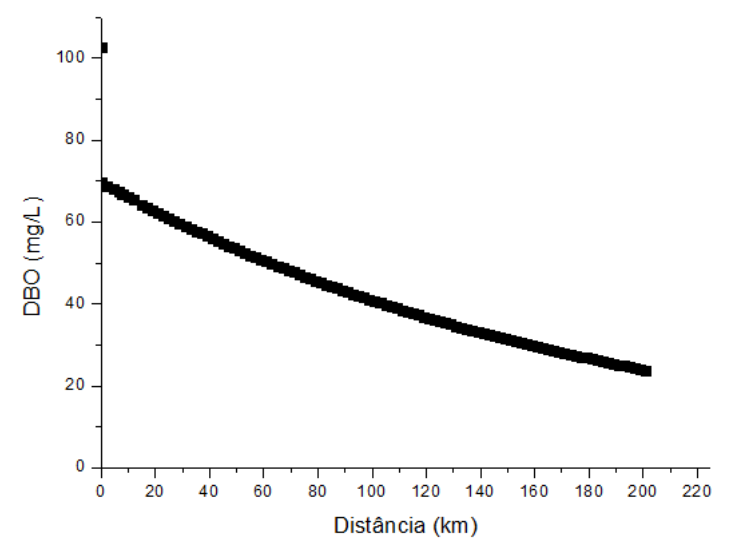

Figura 4. DBO após entrada do tributário.

\section{DISCUSSÃO}

Os perfis de depuração possibilitam a interpretação de uma série de fatos, principalmente relacionado à degradação da matéria orgânica biodegradável pelos microrganismos ali presentes. Observa-se que antes da entrada do efluente tratado pela estação de tratamento de esgotos local, o curso d'água apresenta características sadias, com uma concentração elevada de oxigênio dissolvido $(6,16 \mathrm{mg} / \mathrm{L})$ e baixa quantidade de demanda bioquímica de oxigênio $(8 \mathrm{mg} / \mathrm{L})$, conforme mostra a tabela 1. Tais valores permitem afirmar que o ambiente é propício a manutenção de um ecossistema diversificado.

No entanto, com a entrada o efluente sanitário tratado, 0,32 mg/L de OD e $210 \mathrm{mg} / \mathrm{L}$ de DBO, o cenário do canal se modifica de maneira bastante considerável, principalmente devido as suas características físico-químicas, baixa concentração de OD e elevada DBO, 4,02 mg/L de OD e $103 \mathrm{mg} / \mathrm{L}$ de DBO, seção 2. Dessa forma, a dinâmica fluvial é totalmente afetada, já que existe uma grande quantidade de material orgânico a ser degradado por via biológica, entretanto uma pequena quantidade de oxigênio dissolvido para ser utilizado no processo como um todo.

Contudo, mesmo nesse cenário bastante adverso, os microrganismos presentes no ecossistema aquático retratado efetuam a degradação da material orgânica ali presente, no entanto de maneira lenta, justificando a queda pouco acentuada das curvas representadas pelas figuras 1 e 2. Visto o cenário descrito acima, pode se perceber que até o final desse trecho do rio, 
um cenário de extrema degradação é instalado, percebido principalmente pela grande modificação de variáveis como oxigênio dissolvido e demanda bioquímica de oxigênio. Comparando-se os resultados da seção 1 com as seção 2, percebe-se tal cenário retratado pelos perfis de depuração (Figuras 1 e 2).

Ademais, é importante observar a grande diferença entre a vazão do curso d'água a montante da tubulação de saída da ETE e a do efluente lançado no mesmo, sendo tais dados apresentados na tabela 1, referentes a seção 1 e efluente da ETE. Tal discrepância entre as vazões causa a modificação da dinâmica fluvial local, sendo que onde existe a confluência descrita, é interessante associar as considerações feitas por Poole (2002), em sua teoria da imparidade com o descontínuo fluvial. Isso porque são formadas, pelo menos 2 manchas distintas: aquela ligada a seção onde podem ser observadas as condições iniciais sadias do rio Pirapozinho e o cenário de degradação instalado após o despejo do efluente tratado pela ETE, sendo que nessas duas localidades uma série de fatores são modificados, conforme mostra a tabela 1, seção 2 e as figuras 1 e 2.

Poole (2002) ainda destaca que em situações em que um curso d'água pequeno encontrase com um grande, é possível detectar a jusante um ecossistema parecido com aquele proveniente do curso hídrico maior, não ocorrendo uma transição ecológica. Nesse caso, isso é facilmente perceptível, já que a vazão do lançamento da ETE é muito maior que a do Rio Pirapozinho, e dessa forma as características físico-químicas predominantes estarão ligadas ao efluente, conforme mostram os dados de DBO e OD da tabela 1.

Outro fator importante é a influência do tributário no rio Pirapozinho, podendo associar as considerações a teoria da imparidade com o descontínuo fluvial, em que o gradiente longitudinal do curso d'água principal é modificado pela entrada do tributário. Isso é facilmente observado nas variações significativas que a entrada desse "tributário" (representado pela tubulação da ETE) gera no balanço de oxigênio e material orgânico no curso d'água como um todo.

Todavia, após uma nova confluência com um tributário, de qualidade de água boa, o rio Pirapozinho tem uma melhora em termos de OD e DBO, como pode ser observado pela tabela 1, em suas seções 3, 4 e 5. Isso faz com que o curso d'água principal se aproxime um pouco mais das suas condições iniciais, entretanto, com grande quantidade de matéria orgânica residual, O OD passa a ser consumido para realizar sua estabilização, retornando o cenário de degradação, conforme se vê nas figuras 3 e 4. 
As curvas de depuração apresentadas não tem validade acima de $10 \mathrm{~km}$, já que valores negativos de OD devem ser desconsiderados no processamento da modelagem matemática de Streeter-Phelps (1925), conforme explana Von Sperling (2007). Dessa forma, as figuras 3 e 4 só tem validade até a marca de $10 \mathrm{~km}$. "Caso eventualmente seja calculada uma concentração negativa de oxigênio dissolvido, tal fato, apesar de matematicamente possível, não tem significado físico. Nestas condições, atinge-se a anaerobiose (OD = $0 \mathrm{mg} / \mathrm{L}$ ), e o modelo de Streeter-Phelps passa a não ser mais válido (VON SPERLING, 2007)".

Novamente, percebe-se a aplicação da teoria da imparidade com o descontínuo fluvial, na medida que a ação do tributário altera o gradiente longitudinal do rio, sendo isso percebido nas figuras 3 e 4 e tabela 1 (seção 4 e 5) pela melhoria na qualidade das águas em termos de OD e DBO. Ademais, devido a ação deste, uma nova mancha fluvial pode ser observada, na medida que as características físico-químicas fazem com que esse trecho do curso hídrico tenha características ímpares em relação a outros cursos d'água e até mesmo entre trechos contíguos do mesmo rio.

Nessa situação, pelo fato desses dois corpos terem, mais ou menos o mesmo tamanho e vazão (ver tabela 1), a sucessão ecológica a jusante ocorrerá em uma nova trajetória, sendo que não predominará nem as características do corpo d'água principal nem do tributário, conforme mostra Poole (2002).

\section{CONCLUSÃO}

Pôde-se concluir que a Teoria da Imparidade com o Descontinuo Fluvial, proposta por Poole (2002) pôde explicar os processos ocorridos no canal estudado. Concluiu-se que o canal é um ambiente único na natureza, caracterizado pela presença de manchas bem especificas, resultantes das características do rio e de ações antrópicas, observadas quando ocorre a entrada do efluente no curso d'agua, bem como na confluência do rio principal com seu respectivo tributário modelado. Esta entrada, conforme prevê a teoria, altera de maneira significativa a dinâmica longitudinal Rio Pirapozinho, fazendo com que ocorra melhora ou piora da qualidade das aguas apos a confluência.

\section{REFERÊNCIAS}

CHAPRA, S. Surface Water-Quality Modeling. Long Grove: Waveland Press, 1997

BRAGA, B. et al. Introdução à Engenharia Ambiental: O Desafio do Desenvolvimeno Sustentável. 2 ed. São Paulo: Pearson, 2005 
Encontro de Ensino, Pesquisa e Extensão, Presidente Prudente, 21 a 24 de outubro, 2013

MOTA, S. Introdução à Engenharia Ambiental. 3 ed. Rio de Janeiro: ABES, 2003

POOLE, G.C. (2002). Fluvial landscape ecology: addressing uniqueness within the river discontinuum. Freshwater Biology, 47: 641-660. http://dx.doi.org/10.1046/i.1365$\underline{2427.2002 .00922 . x}$

SILVA, G.H.G. Curso de limnologia. Caraubas: UFERSA, 2011

SIQUEIRA, R. M. B.; HENRY-SILVA, G. G. A bacia hidrográfica como unidade de estudo e o funcionamento dos ecossistemas fluviais. Boletim da Associação Brasileira de Limnologia - 39(2). 2011.

VANOTE, R. L. et al (1980). The river continuum concept. Canadian Journal of Fisheries and Aquatic Science. 37(1): 130-137. http://dx.doi.org/10.1139/f80-017

VON SPERLING, M. Estudos e modelagem da qualidade de água de rios. 3 ed. Belo Horizonte: DESAUFMG, 2007. 